\title{
Provision of Public Health and Covid-19: A Case of Responsibility Evasion in India
}

\author{
Ishfaq Ahmad ${ }^{*}$, Md. Sarafraz Equbal \\ Department of Economics, University of Kashmir, India \\ Email: ishfaqmajeed.ku@gmail.com
}

Received: 05 June 2021; Revised: 22 January 2022; Accepted: 27 January 2022

\begin{abstract}
This study will analyse the overtime public spending in public health (1990-2020) and will also try to highlight how covid-19 pandemic can be a reminder to the government of its public health responsibilities it has been partially evading for too long. Covid-19 pandemic has led to emergence of macroeconomic crises inflated by public health crises. The public policy response to the pandemic has been to choose between twin alternatives of "Livelihood saving versus Life-saving". A closer examination of the two crises reveals that the Livelihood crises to a large extent was magnified by lifesaving policies in emerging economies like India. Due to weak public health infrastructure these economies were forced to undergo abrupt and harsh lockdowns. In face of inadequate health infrastructure, the lockdowns were the only strategy left with the government-leading to classic supply side shock to macroeconomic aggregates. The inadequacy of health infrastructure can be primarily associated to a consistent tendency on the part of Indian government to evade its public health responsibilities. As of 2018-19 government has allocated 1.9 percent of its national income to health sector as against the standard norm of 3 percent. Apart from "good for growth argument" investment in health care is an important welfare target and a pre-condition to sustained economic growth. Apart from absolute inadequacy, the study found an asymmetric distribution of health infrastructure in the country.
\end{abstract}

Keywords: Covid-19, lockdowns, national income, public health

JEL Code: H00, H4, H51, H60, H75

\section{Introduction}

Covid-19 Pandemic is a global humanitarian crisis that disrupted every aspect of human life across countries. It started as a health crisis and then culminated into an economic disaster. The three main channels of transmission that magnified the economic impact of the pandemic include Supply shock, Demand shock, credibility and confidence shock. The pandemic disrupted the global supply chain due to factory closure, labour migration and choking off many service sector activities. The demand shock mainly culminated via the reduced business, tourism and educational services. The credibility shock mainly engulfed due to uncertainty emanating from reduced or delaying consumption of goods and services and thus impacting the tendency of investors to undertake fresh investments (Rangan \& Chakraborty, 2020).

Copyright (C2022 Ishfaq Ahmad, et al

DOI: https://doi.org/10.37256/ges.232021976

This is an open-access article distributed under a CC BY license

(Creative Commons Attribution 4.0 International License)

https://creativecommons.org/licenses/by/4.0/ 
These disruptions and consequent downswing in economic activity primarily drew from the policy response of choosing between life-saving versus livelihood saving strategies.

Most of the countries responded using lockdowns to mitigate the humanitarian crises created by Covid-19 pandemic given the inadequate health infrastructure (Kooli, 2021). They preferred saving life over saving livelihood by undergoing harsh lockdowns to contain the transmission of virus. However, the strategy of persistent lockdowns has an inherent tendency to create humanitarian crises by fostering hunger and starvation of marginalised and daily wagers. Though this life vs. livelihood trade-off was faced by almost every country but its differing intensity across countries was impacted by two determinants. First, the age matrix of the country i.e. the proportion of population that was most susceptible and likely to be infected especially the aged ones. For instance the European countries with significant old age population were badly hit and accordingly the intensity of trade-off i.e. saving life with the livelihood forgone was high. Second, the level of health infrastructure that was available in an economy. For instance, economies like India, Pakistan and Bangladesh had favourable age matrix and initially very few people were infected (India had $65 \%$ of population less than 35 years of age). But due to poor and insignificant health infrastructure these economies undertook severe and strict lockdowns.

The lockdowns seem to be the only strategy left with these economies to mitigate the impacts of a health disaster. The Indian economy was caught off-guards mainly because of the insensitive policy response to forecast the crises besides a weak and crippling public health infrastructure. The lockdowns were the only option left to buy time for fractured health sector of the country to respond and develop the absorptive capacity. However, these persistent lockdowns inversely resulted in both an economic and a health contagion. The economic contagion resulted due to complete disruption of supply chains and thus economic activity. Further loss of employment and consequent purchasing power to the poor and marginalised sections of the society resulted in a demand shock to the economy [According to Centre for Monitoring Indian Economy (CMIE) the unemployment stood at around 8.7 percent in March 2020 and then increased to 10.7 percent in April 2021 following the second wave]. The health contagion resulted due to mismanaged labour movement from cities to rural areas without considering any standard operating procedures (SoPs) thus leading to lightening transmission of the disease across the country.

This led to huge stress on the health sector of the country that almost crumbled as the shock was many times greater in magnitude than what the health sector can absorb. This was primarily on account of an unaddressed historical infrastructural vacuum in the health sector of the country. These infrastructural deficiencies persistent in the Indian health sector can be broadly categorised into physical infrastructure deficiencies and deficiencies in manpower. In order to overcome the acute physical infrastructural deficiency, the government responded by converting schools and other government buildings to short term hospitals and quarantine centres. This strategy provided the much needed short term relief as it allowed health sector to buy time to adjust to the shock. However, the manpower shortage especially in the form of specialised doctors and paramedical staff continued. Though the government tried to hire the paramedical staff on a contract basis but this could not provide much relief given the inability of new staff to handle such crises without any experience. The overall inability of the health sector to handle the crises was primarily because of consistent low spending in public health by successive governments.

In this backdrop the study will try to address the following objectives:

- To have an overview of current health sector spending in India.

-To highlight how Covid-19 pandemic aggravated the existing fractures of Public Health.

The study is a descriptive attempt to factor out how Indian public policy over time has evaded its responsibility of public health that was badly exposed by Covid-19 crises. The study is covered as: section II will be discussing the literary background in terms of both making a case for public spending in public health and the historical overview of government spending in public health. Section III will highlight the legal aspects like who has the constitutional responsibility to invest in public health. Section IV will be analysing the overtime budgetary allocations to the health sector and Section V will highlight how these budgetary allocations translate into health infrastructure across the country. Section VI will present a brief comparative analysis of how other emerging market economies of comparable size are investing in their public health. Section VII quoted some policy recommendations. The study will be concluded by section VIII. 


\section{Literature survey}

\subsection{Case for public spending in public health}

In his seminal work, Romer (1986) highlighted the shortcoming of aggregate growth models of Ramsey (1928), Cass (1965) and Koopmans (1963). The basic premise underlying these growth models states that investment returns and per-capita growth rate of output are expected to be a decreasing function of capital stock in the long run. According to these models, growth rates across countries are expected to converge to a steady state with no further increase in net per-capita growth of income. An alternative model with a complete departure from the above-cited growth models was put forward by Romer (1986). The level of per-capita income across countries need not converge and in case of underdeveloped economies growth may be persistently slower or may even fail to take place at all. Romer (1986) holds that in a competitive economy per-capita output may grow without an upper bound, possibly at a rate that is monotonically increasing even in long run.

The underlying reasoning for these conclusions directly derives from a long-run growth model in which growth is primarily driven by the accumulation of knowledge by forward looking, profit maximising economic agents. The basic element that reverses the standard findings of the conventional growth models is the assumption of increasing rather than decreasing marginal productivity of capital good Knowledge. Knowledge is a function of the spending on research and development. Spending in Research and Development is broadly categorised under three headings namely Basic $R \& D$, Applied $R \& D$ and Developmental $R \& D$ (Grosse, 2020). Basic $\mathrm{R} \& \mathrm{D}$ spending is typically the domain of government both in advanced and emerging economies. The basic R \& D broadly constitutes the social overhead capital in the form of spending on health and education. So it is imperative on part of the government to undertake social sector spending to create knowledge. This knowledge capital is then assumed to be a perfect substitute for physical capitalwith the former having increasing returns rather than decreasing returns as is the case with the latter.

Apart from the good for growth argument, public spending in health and education are important welfare goals in themselves (Mundle, 1998; Baldacci et al., 2008). This has been mainly on account of increasing dissatisfaction with growth per-capita being too the narrow and inadequate measure of human welfare [One of the most prominent reason for this dissatisfaction primarily drew from the fact that growth of GDP per-capita at large is insensitive to distributional aspects]. The increasing inability of the growth rate of income to explain the persistent poverty and exclusion started to mount from the 1970's. Accordingly, an alternative view of measuring development based on different indices ranging from basic needs (Pigou, 1951) to quality of life (Sen, 1973) was undertaken. The United Nations developmental programme (UNDP) finally formalised the use of index based measures of development in the form of Human Development Index, 1990. The conceptual foundation of this approach can be found in the work of Amartya Sen (Anand et al., 1993). Most of these indices are based on the social and welfare indicators primarily financed by public spending both in emerging and advanced economies. Thus this approach to development established the role for public policy to help the countries augment the human capital for sustained long-run economic growth (Baldacci et al., 2008). This led to the genesis of a tendency to depart from the conventional market-driven approach of "Invisible hand" to the "Visible hand" of the state policy.

The effectiveness of the visible hand of state policy to foster the growth of human capital has been established in case of exceptional growth performance of the East Asian Tigers (Rao, 1998). In case of four high-performing Asian economies of Japan, South Korea, Singapore and Taiwan, Rao (1998) highlighted how effective use of public policy helped these economies to register long-term sustained economic growth with healthy income distribution across sections. Baldacci et al. (2008) arrive at similar conclusions in a panel study of 118 countries. They documented a strong and positive impact of public spending on the long run economic growth of these economies. However, apart from spending on health and education the study contends for the role of better governance in long term growth. Mundle (1998) analysed the role of public policy to finance the human development in advanced East Asian Economies. They argued that there is an inescapable role for public policy to undertake the provision of primary health and education. However, for higher health standards and higher education, the public-private partnership (PPP) model may be more appropriate model.

In case of emerging economies like India, the state intervention regarding the provision of public utilities is justified for at least two additional reasons apart from the good for growth argument. First, the market on its own cannot guarantee equitable distribution of gains from growth and second, the markets have a tendency to "market 
failures". Since the provision of public utilities has properties like public goods, the markets cannot rely for an optimal provision of these goods. In case of the Indian economy, extent literature has pointed to the fact that public policy has a significant role in the creation of human capital thus long run economic growth. Mukherjee (2007) highlighted the role of public policy for the creation of human capital through spending in health and education. The state intervention for the provision of merit goods like health and education primarily follows from the divergence between social and private returns from social sector spending. Similarly, Chopra (2002) holds that an evolving and increasing stock of capital forms a necessary input for the sustained growth in the case of the Indian economy. However, they also stressed the role of institutions in complementarity to the level of public spending for effective outcomes.

\subsection{Government spending in public health: A historical overview}

Post-independence India has made a huge success in many areas spanning from chronic poverty to space missions. But there are areas that have either received skewed policy attention or no attention at all. The health sector is a case in question. Horton and Das (2011) highlighted that there exists a paradoxical scenario so far as the Indian health sector in the Indian the political landscape is concerned. There is a huge potential for public debate to put public health high on political agenda. But health is rarely a decisive political issue in Indian politics whether national or state. The public spending on health in India is one of the lowest in the south Asia. The burden of infectious disease remains inadequately controlled that has been badly exploited by the current pandemic. Apart from infrastructural deficiencies, India suffers deep inequalities across regions mainly because of insufficient government budgetary allocations to the health sector.

Narayan (2011) contends that Indian economic model overtime has increased the disparity in the health sector rather than wipe-out these inequalities. The hallmark of Indian public policy has been to promote medical tourism at the cost of universal primary healthcare. The primary implicit objective of Indian public policy has been to place the market cause above the cause of people. Equity, affordability and public good considerations should have been the focus of health sector reforms rather than market and profits. These policies with an explicit intent favouring markets have led to affordability crises in Indian health sector. Sen (2011) further corroborated the findings of Narayan (2011) regarding the gross inequality in health care delivery in India. On one hand there are flourishing international medical tourism and high technology biomedical interventions done cheaply on the other side minimum health care is unavailable or unaffordable for marginalised. The author holds that the basic determinants of social health such as healthy food, safe drinking water, better sanitation is a distant dream for most of the vulnerable sections of the society. Many research reports have pointed out that overtime consumption of food grains has deteriorated especially for below poverty people. Similarly, slow improvement in Infant mortality rates, low child immunisation and widespread malnutrition points to the fact that inequality in social determinants in social health care in a market based system itself becomes a pathogenic factor that fuels the engine of deprivation.

Grover and Citro (2011) argued that the reintroduction of patent protection under the agreement on Trade Related aspects of intellectual Property rights (TRIPS) has adversely impacted both accessibility and affordability of health services in India. The reinforcement of these agreements has put huge pressure on the production of low-cost generic drugs in India. For instance, India signed a free trade agreement with European Union with a prime motive to introduce TRIPS-plus agreement. This includes measures such as patent-term extensions, data exclusivity, increased enforcement measures and investment protection. All these measures have greatly impeded the competition from generic drug competition leading to a huge overtime increase in out of pocket health expenditure. The authors even argued this increased out of pocket health expenditure has pushed many families below the poverty line.

In a similar study Rao et al. (2011) found that apart from inadequate attention from public policy there are many other challenges that Indian health sector is riddling at large. Firstly, there is an acute shortage of skilled and qualified manpower and second, there are growing disparities in terms of health services provided in urban and rural areas. The study found that $80 \%$ of outpatient visits and $60 \%$ of hospital admissions are in the private sector. Consequently, $71 \%$ of health spending is out of pocket, and, every year, such expenditure forces $4 \%$ of the population into poverty. The other façade of the problem is the skewed distribution of already limited infrastructure both human and physical. Most of the doctors and nurses prefer to serve in urban areas rather than in rural areas. There have been certain flagship schemes like National Rural Health Mission (NRHM) to address the issue. But the progress so far has not been satisfactory and the cracks became more visible during the Covi-19 pandemic. Dandona et al. (2011) argue that India still has the largest disease burden of any country, the mitigation of which requires significant policy intervention. The public policy needs 
to speed-up its efforts to undertake long term research and development expenditure for pressing health issues. There is a significant number of diseases both communicable and non-communicable that are either under reported or not reported at all.

In case of the Indian economy, public health is a state subject. However, there is increasing scholarly indication towards the fact that states evade their responsibilities at least for two reasons. First, it has been empirically established that in face of fiscal shocks the states resort to reducing their spending in health and education to maintain their fiscal balance (Chakraborty et al., 2017; Khoja et al., 2020). Second, the states exhibit a declining tendency of spending in health and education mainly under the shadow of increasing central spending (Shariff et al., 2002). Apart from responsibility evasion, there are huge inter-state variations in spending on health and thus consequently impacts the efficiency of public spending (Mohanty \& Bhanumurthy, 2018). In case of Indian economy there is a paradox between overall public expenditure and the social sector spending by the government. The UNDP has proposed a 25 percent of GDP for public expenditure, 40 percent of this public expenditure should be devoted to social sector spending, 50 percent of this social sector spending should be devoted to human capital (Dev et al., 2002). Apart from this 5 percent of GDP should be devoted to human capital formation. As against these prescribed norms, India has a public expenditure of 37 percent. The social allocation and social priority in the form of human capital are around 20 percent and 34 percent. Moreover, India spends less than 3 percent directly for human capital formation. Though, India has a huge public sector expenditure but this could not be translated into healthy social sector spending thus pointing towards the fact that India is trying its best to evade its public responsibilities.

Not only historically, but the public policy at large has also been insensitive to vacuums and shortcomings of health sector infrastructure even during the Covid-19 crises. In one of the editorial commentaries in Economic and political weekly, the writers argued that the second wave of Covid-19 was to a large extent man-made disaster. This is precisely on the grounds that even if the government had a time span of more than 1 year to boost up its health infrastructure. But government choose to be deaf that led to unimaginable pain and loss of precious lives. Since independence the health sector spending has never crossed the mark of 2 percent of GDP. However, the international norms demand it to be in between 3 to 3.5 percent of GDP. Due to this lower spending in the health sector, India has just 1 bed per 1820 population while as its 3 beds in Srilanka and 4 beds for china. Similarly, in terms of manpower, World Health Organisation (WHO) recommends 1 doctor per 1000 population and 1 nurse per 1000 population. But in case of India this ratio is 1511 persons per doctor and 1670 persons per nurse. Apart from meagre spending in health by centre government, there are huge interstate disparities in health spending and consequent health services. The per-capita health expenditure in Bihar is Rs. 617 while that of Kerala is Rs. 2048 and for Goa is Rs. 6207. Similarly, Khoja et al. (2020) found that the fiscally better performing states spend least on health and education as against the states that report fiscal indiscipline.

\section{Who finances health in India}

The legal obligation to finance health sector spending in India rests on Indian states. This obligation mainly derives from the constitutional arrangements of power distribution between centre and state governments. However as pointed out in the literature that there are many challenges that states have to face while allocating resources for health and education. The very first technical issue confronting the social and welfare spending is its discretionary nature. The states are not bound by any rule to maintain a certain level of welfare spending in health and education. Because of this discretionary nature the states either underspend in these public utilities or in face of any fiscal pressure they find it convenient to reduce this spending (Chakraborty et al., 2017; Khoja et al., 2020). The second issue pertains to the structure of fiscal federalism where-in there is dis-equilibrium between revenues and responsibilities of the states. It has been long established that states of Indian union are left with meagre resources while as they have to finance a huge set of responsibilities. So after budgetary allocations for different committed heads of expenditure, the state governments are left with almost no resources to finance an ever expanding demand for public goods in the form of public health and education. The third challenge emanates from the fact that there are acute differences across states so far as their health sector spending is concerned. As pointed already Bihar spends the least per-capita income on health while as Goa and Kerala spend the most.

However, overtime the centre government has stepped in to partly pacify the huge vacuums in the health 
infrastructure that primarily is the state subject. Through various centrally sponsored schemes like National Rural Health Mission (NRHM) the centre government has tried to address this disequilibrium to some extent. However, there are issues with central spending as well. The most cited criticism of centrally sponsored schemes is their inherent "single design fit for all". In face of acute asymmetries of information these central interventions are always going to lead to socially suboptimal outcomes. So in essence it violates the basic premise of gross root level decision making and is likely to breed inefficiencies. Because of this asymmetric information these centrally sponsored schemes are found to over spend for certain states and under-spend for others. Since these centrally sponsored schemes are based on the principle of equity in access to public health across the country, thus states with unfavourable health sector infrastructure are expected to gain more. This has led to the tendency on part of states to compete for the resources by underperforming in their budgetary allocations. So in essence such a centralised intervention dis-incentivises the best performing states and rewards those that perform badly.

\section{Social sector spending: How does health spending reflect in our budgets}

As has been already pointed that public health has never been a priority on the political agenda in India despite being one of the most vibrant democracy in the world. This has led to a persistent underspending in the health sector both on part of states as well as centre. Apart from a few national level programs concerning the health sector spending like National rural health mission the central government has not paid due attention to public health across the country. This lack of public interest in the public health reflects in the budgetary allocations over time. The public spending as a proportion of national income has never crossed the 2 percent mark. This is very low than the warranted public health spending of 3 percent for an economy like India [The figures quoted here are the combined state and central spending in public health].

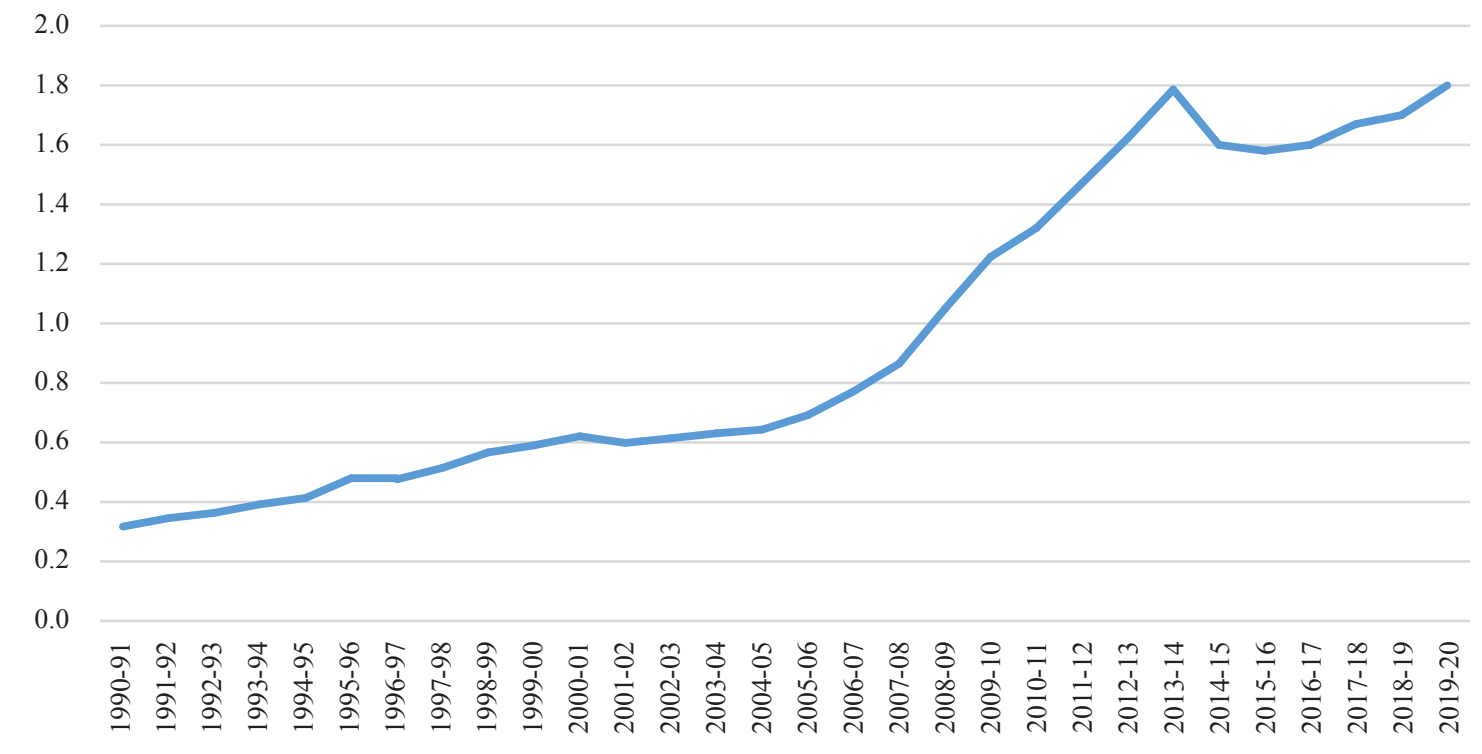

Figure 1. Public Health spending percentage of GDP Source: Compiled by Authors using data from EPWrifts

This low level of public spending for public health is miserably reflected in the form of inadequate health infrastructure in the country. For a population of around 1.4 billion we have just 7 All India Institutes of Medical Sciences (AIIMS) that undertake basic research in public health and hygiene as of 2019 [Although we have an official list of 22 AIIMS institutes but at present just 7 of them are functional. Other are either under construction or partially 
working with basic OPD Units]. As of May 8, 2020 we have around 2500 Covid-19 testing labs in India with more than 50 percent being private labs. Out of the total more than 70 percent are located in urban and semi urban areas. A weak public health infrastructure with an adverse distribution between rural and urban areas challenges the right to health and safe hygiene to the rural poor. The government has failed to provide even basic preventive healthcare services such as safe drinkable water and sanitation. Only 30 percent of rural India have access to piped water supply and 43 percent have access to safe toilet facilities (Rao, 2017). India has per-capita budgetary spending of Rs. 96 as of 2020 while as for china it is more than 150. Even Bangladesh, Srilanka and Bhutan spend more in terms of per-capita. This consistent under spending in public health has led to an exponential increase in the out of pocket expenditure on health services by households. Rao (2017) quoted that out of pocket expenditure is five times the public spending and is the most profound cause of immiseration of the poor.

As mentioned health is a state subject and accordingly around 85 percent of health spending is undertaken by states. Though these numbers sound promising but an in-depth analysis reveals the stark caveats so far as the demand for and supply of public health is concerned. An analysis across states in terms of their per-capita expenditure on health services presents a very sorry state of affairs. The Bihar is the lowest spending state spending around Rs. 540 per-capita while as Kerala spends around 4 times that of Bihar at around Rs. 2000 per-capita.

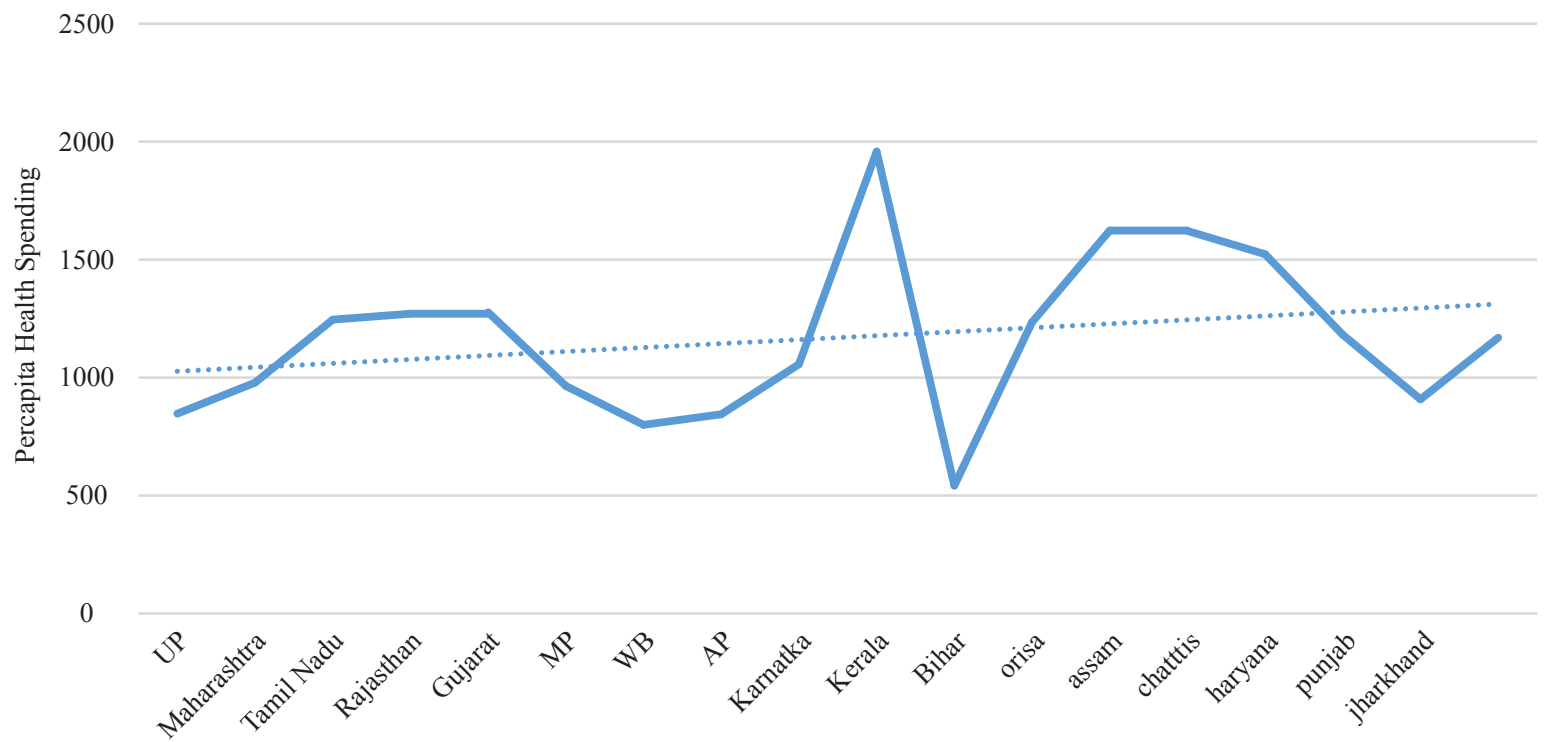

Figure 2. Per-capita Health expenditure of selected states as of 2019 Source: Compiled by authors using data from EPWrifts

Apart from Bihar, UP and WB are also doing miserably in terms of health sector spending. These three states constitute around 33 percent (45 crore people) of countries population and are spending less than Rs. 1000 per-capita in health. It implies a population equal to the whole of Europe (less of Russia, Germany and UK) is without access to adequate health facilities in just three states of India.

State spending on health, apart from skewed distribution across states, has certain compositional aspects that hinder the long term growth of robust health infrastructure in the country. More than 90 percent of state spending on health is spent on the revenue account of the sector. This implies that these expenditures are mostly undertaken to finance the committed expenditures like salaries and other daily expenses. A very meagre proportion of about 7 to 8 percent is spent on capital heads meant for creation of new infrastructure. As can be seen through-out the reference period there is an increasing divergence so far as the nature of state spending in public health is concerned. A glimpse from the graph below may give an impression to the reader that states are performing better in terms of increasing the man power in the sector. However, in face of a huge already existing shortfall in terms of human capital, these trends are taken to mean 
that the health sector is working with the basic minimum staff available. The health allocations across Indian states are so low that a disproportionately huge share is absorbed by just current expenses. Coupled with least or minimal support from centre government, the infrastructure development is going at a snail's pace. This over-all underspending on one hand and disproportionately huge spending on just funding the current expenses poses substantial challenges for the health sector to cater to the increasing demand for public health. This to a large extent can explain the devastating scenario that Indian economy had faced during the second wave of the pandemic. The inability to provide adequate oxygen to the patients on ventilators needs to be assessed through a time-tested the reality of consistent under spending in public health.

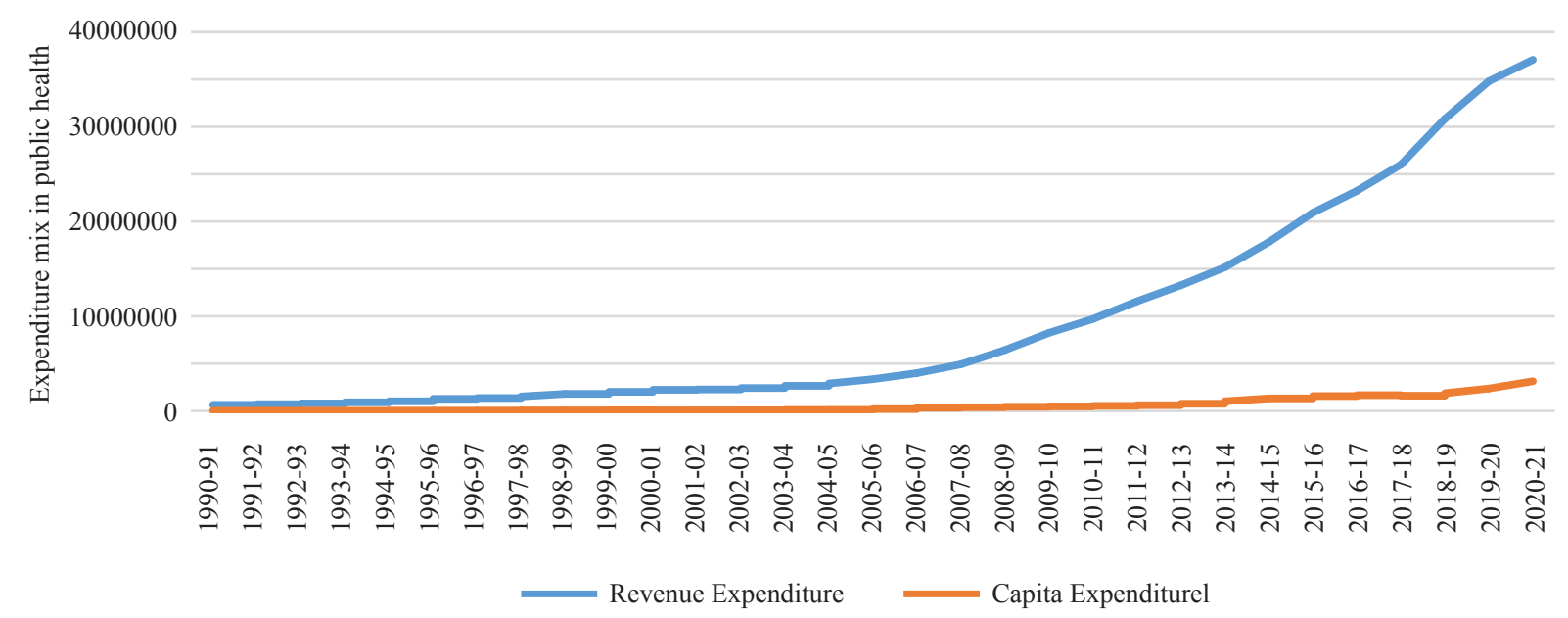

Figure 3. Overtime revenue and capital account spending in health Source: Compiled by authors using data from EPWrifts

\section{How does under-spending in health reflect in health infrastructure}

Extent literature has pointed towards the critical imbalance between the demand for and supply of public health in India mainly emanating from lower public spending. India has one of the highest incidences of out of pocket expenditure on health, more so for the poor and marginalised. As pointed already that because of this many families are forced into the poverty and starvation due to non-affordability of health. Apart from affordability issues, the public health services are sparsely distributed with more concentration in urban rather than rural areas. So accessibility of public health is a peculiar challenge for the poor and marginalised in India. Around 67 percent of India lives in rural villages but a very minimal amount of public health is attributed to rural areas. This imbalance between demand and supply of public health in rural areas is reflected in crude ratios. For instance, the infant mortality rate for rural areas is around 68 while as for urban areas it's 36, almost half of rural areas.

The weak budgetary support for a redundant health sector is the prime reason for the current crises in health services of the country. Except for the special category states, in all other states the number of private hospitals is much greater than public hospitals. Since these private hospitals are market-oriented with a primary motive to raise profits. So one cannot rely on these private institutes to supply a public good with vast positive externalities. Besides the quantity of public health institutions, the quality also carries a question mark. There are acute variations in terms of government hospitals and specialised staff working. The doctor-patient ratio is adverse and it was astonishing to find that over time this ratio has further aggravated. In 2005 there was a shortfall of around 1000 doctors in rural primary health centres across India. By 2019 this short fall increased to around 1500, experiencing an increase in shortage of doctors by around 50 percent (NRHM, 2019). It was found that on average all the states have drastically reduced the number of doctors sanctioned for these primary and community health centres. However, in case of urban areas the doctor-patient ratio was slightly favourable as compared to rural areas. 
A similar trajectory was reported in other indicators like hospital beds per thousands of populations, a number of nurses, etc. As of 2019, the overall hospital beds to population ratio was 1820 persons per hospital bed for all over India. The same ratio was 870 persons per bed in urban areas whereas in case of rural areas the ratio was 3430 persons per bed. Bihar and UP were found to states with the worst hospital beds to population ratio while as small and special category states were found to have favourable ratios. In a generalised scenario for an overall economy the supply of public health significantly lags demand for public health. So basic economics holds that a demand supply divergence will lead to a price rise thus questioning the affordability of the utility in question.

\section{How other emerging market economies are spending on health}

As already mentioned India has the highest out of pocket health expenditures by its citizens in the world. Overtime India has not made much progress in addressing this vacuum when compared to other economies of the world. For instance, China and India have somewhat similar out of pocket expenditure ratios during 1999-2000. However, by 20182019 , China has managed to reduce this ratio to around 35 percent while as India has a ratio of 62 percent. Surprisingly, from 2011 to 2013 this ratio increased rather than experiencing a decline as was observed in most of the nations. Apart from China, India is performing worse than Bhutan and Srilanka in terms of the incidence of health burden on its citizens. The out of pocket expenditure in Bhutan and Maldives is less than 20 percent implying lower than $1 / 3^{\text {rd }}$ of Indian scenario. Similarly, India has the lowest Per-capita Community health Expenditure (PCHE) in the group of BRICS. In 2000 India was spending 1/2 (one-half) of what china was spending in terms of per-capita on health. By 2018 this difference has increased to 8 times implying India is spending $1 / 8^{\text {th }}$ of what China is spending on community health. Brazil is spending 11 times more on community health than India, Russia is spending 6 times more than what India is spending and South Africa is spending 7 times more than India on public health.

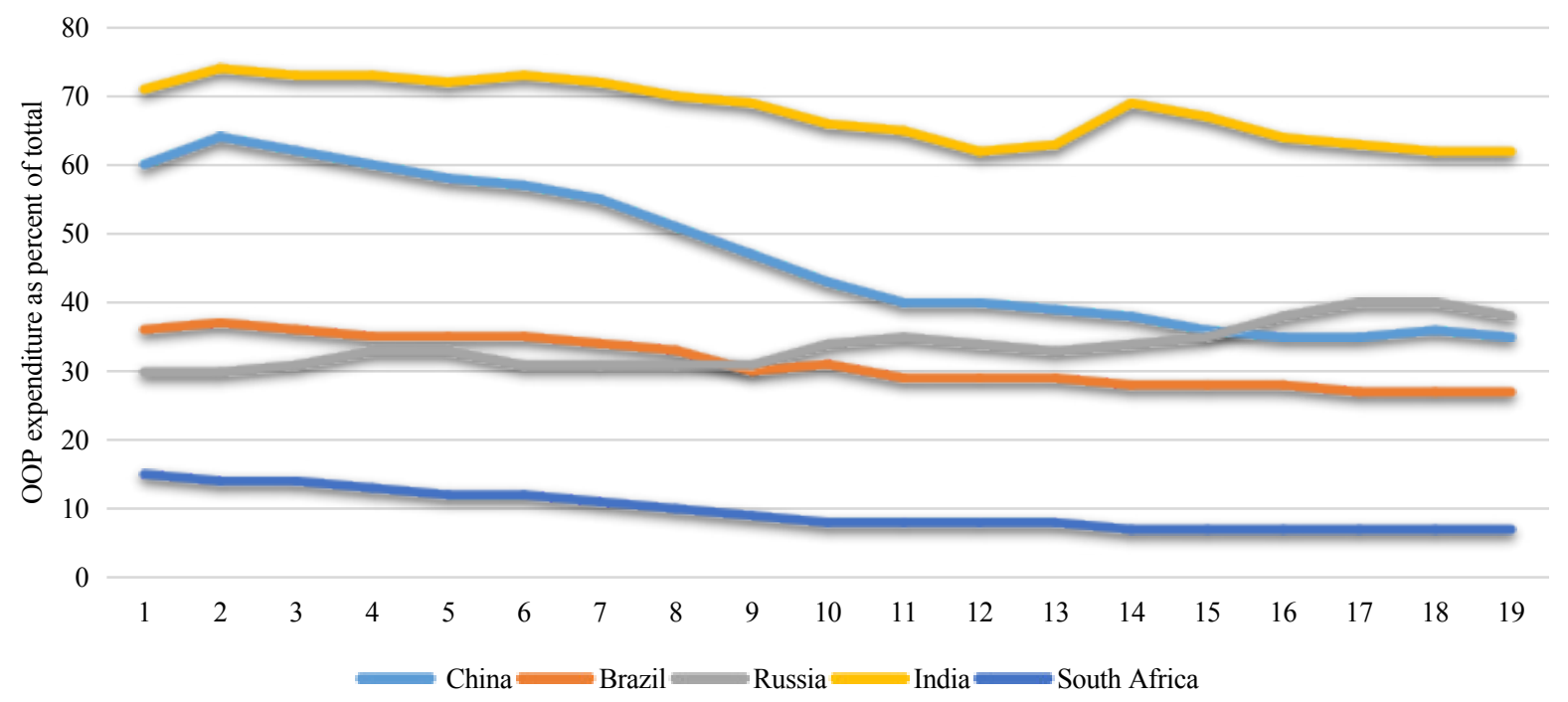

Figure 4. Overtime out-of-pocket expenditure by citizens of the country

Source: Compiled by authors using data from World Health Organisation

Moreover, Srilanka is spending more than 2 times on community health than India, the Maldives is spending 13 times and Bhutan is spending almost 1.5 times greater on community health than India. In South Asia India is the second worst performing state in terms of public health the first being Pakistan. This underspending in public health is very much reflected in the share of total health spending financed by the government. In 2000 around 20 percent 
of health expenditure was undertaken by the government and it rose to 27 percent by 2018. During the same period this proportion in case of China rose to 58 percent in 2018 from 22 percent in 2000. In case of South Africa the ratio increased from 37 to 54 percent during the reference period. For the reference period this ratio has increased from 34 percent to 70 percent in case of a tiny island nation Maldives [Most of the data quoted in this para have been extracted from World Health Organisation (WHO)]. All these figures point to the fact that due to the consistent underspending in public health, the burden of public health that otherwise should have been a government responsibility is born by poor and marginalised sections of the society.

\section{Policy recommendations}

Some of the policy recommendations that follow include:

- The nature of health spending needs to change from discretionary to obligatory and the same should be incentivised through different fiscal instruments.

-The Union government needs to step in to take the whole responsibility of financing the physical infrastructure in the health sector, leaving current expenditure the state domain.

-Medical tourism needs to be regulated and private partners need to bear their share of responsibility.

-The public policy needs to pay due attention to the distribution of public health in the country with backward states carrying the special focus of the policy.

\section{Conclusion}

India is an emerging economy with a huge population below the poverty line. This makes it imperative on part of Indian public policy to invest in areas of social importance. The two most important areas that need strong intervention from the government are public health and education. However, it is unfortunate to reconcile with the fact that public health does not carry any significant importance in Indian political landscape. This has led to a historical underspending in public health due to a consistent tendency on part of the public policy to evade its responsibilities towards its citizens. This consistent responsibility evasion in terms of underspending in public health stands badly exposed by Covid-19 pandemic. So the pandemic on one hand has exposed the historical complacency on part of public policy to invest in public health. On the other hand, it's a reminder for both the public and government to put public health high on political agenda rather than resorting to responsibility evasion as has been the historical drama on display.

\section{Conflict of interest}

The author declares no competing financial interest.

\section{References}

Anand, S., \& Ravallion, M. (1993). Human development in poor countries: On the role of private incomes and public services. Journal of economic perspectives, 7(1), 133-150.

Baldacci, E., Clements, B., Gupta, S., \& Cui, Q. (2008). Social spending, human capital, and growth in developing countries. World development, 36(8), 1317-1341.

Cass, D. (1965). Optimum growth in an aggregative model of capital accumulation. The Review of economic studies, $32(3), 233-240$.

Chopra, K. (2002). Social capital and development processes: Role of formal and informal institutions. Economic and Political Weekly, 37(28), 2911-2916. https://www.jstor.org/stable/4412361

Chakraborty, P., \& Dash, B. B. (2017). Fiscal reforms, fiscal rule, and development spending: How Indian states have performed? Public Budgeting \& Finance, 37(4), 111-133.

Dandona, L., Katoch, V. M., \& Dandona, R. (2011). Research to achieve health care for all in India. The Lancet, 
377(9771), 1055-1057.

Dev, S. M., \& Mooij, J. (2002). Social sector expenditures in the 1990s: Analysis of central and state budgets. Economic and Political Weekly, 37(9), 853-866. https://doi.org/10.2307/4411812

Grosse, R. (2019). Innovation by MNEs in emerging markets. Transnational Corporations, $26(3), 1$.

Grover, A., \& Citro, B. (2011). India: Access to affordable drugs and the right to health. The Lancet, 377(9770), 976977.

Horton, R., \& Das, P. (2011). Indian health: The path from crisis to progress. The Lancet, 377(9761), 181-183.

Khoja, I. A., \& Khan, N. A. (2020). Fiscal legislation, debt management and social spending: A state-level analysis in India. IUP Journal of Applied Finance, 26(1).

Kooli, C. (2021). COVID 19: Public health issues and ethical dilemmas. Ethics, Medicine and Public Health, 17, 100635. https://doi.org/10.1016/j.jemep.2021.100635

Koopmans, T. C. (1963). On the concept of optimal economic growth (No. 163). Cowles Foundation for Research in Economics, Yale University.

Mundle, S. (1998). Financing human development: Some lessons from advanced Asian countries. World Development, 26(4), 659-672.

Mukherjee, A. (2007). Public expenditure on education: A review of selected issues and evidence. Working Papers id: 856, eSocialSciences.

Mohanty, R. K., \& Bhanumurthy, N. R. (2018). Assessing public expenditure efficiency at Indian states. National Institute of Public Finance and Policy, New Delhi, NIPFP Working Paper, 225.

Narayan, R. (2011). Universal health care in India: Missing core determinants. The Lancet, 377(9769), 883-885.

Pigou, A. C. (1951). Some aspects of welfare economics. The American Economic Review, 41(3), 287-302.

Ramsey, F. P. (1928). A mathematical theory of saving. The Economic Journal, 38(152), 543-559.

Rangan, D., \& Chakraborty, L. S. (2020). COVID-19: Global diagnosis and future policy perspective. National Institute of Public Finance and Policy.

Rao, M. G. (1998). Accommodating public expenditure policies: The case of fast growing Asian economies. World Development, 26(4), 673-694.

Rao, M., Rao, K. D., Kumar, A. S., Chatterjee, M., \& Sundararaman, T. (2011). Human resources for health in India. The Lancet, 377(9765), 587-598.

Rao, M. G. (2017). Public finance in India in the context of India's development. National Institute of Public Finance and Policy, New Delhi.

Romer, P. M. (1986). Increasing returns and long-run growth. Journal of Political Economy, 94(5), 1002-1037.

Sen, A. (1973). On the development of basic income indicators to supplement GNP measures. UN Economic Bulletin for Asia and the Far East 24.

Sen, B. (2011). Securing the right to health for all in India. The Lancet, 9765(377), 532-533.

Shariff, A., Ghosh, P., \& Mondal, S. K. (2002). State-adjusted public expenditure on social sector and poverty alleviation programmes. Economic and Political Weekly, 37(8), 767-787. 